\title{
Population Structure and Genetic Variability of Angus and Nellore Herds
}

\author{
Vanius B. Falleiro ${ }^{1,4}$, Carlos Henrique M. Malhado ${ }^{1,3}$, Ana Claudia M. Malhado ${ }^{2}$, Paulo Luiz S. Carneiro ${ }^{1}$, \\ José A. Carrillo ${ }^{3} \&$ Jiuzhou Song ${ }^{3}$ \\ ${ }^{1}$ Universidade Estadual do Sudoeste da Bahia, Av: José Moreira Sobrinho, S/N, Jequié, Bahia, Brazil \\ ${ }^{2}$ Universidade Federal do Alagoas, Maceió, Alagoas, Brazil \\ ${ }^{3}$ University of Maryland, College Park, Maryland, United States \\ ${ }^{4}$ Instituto Federal Catarinense, Rio do Sul, SC., Brazil \\ Correspondence: Vanius B. Falleiro, Universidade Estadual do Sudoeste da Bahia, Av: José Moreira Sobrinho, \\ S/N, Jequié, Bahia 45200-000, Brazil. E-mail: carlosmalhado@gmail.com
}

Received: August 25, 2014 Accepted: October 28, 2014 Online Published: November 15, 2014

doi:10.5539/jas.v6n12p276 URL: http://dx.doi.org/10.5539/jas.v6n12p276

\begin{abstract}
Reproductive isolation of cattle herds should have significant negative genetic consequences, including inbreeding depression and the loss of diversity through genetic drift. Cattle herds may also suffer detrimental effects on genetic variance caused by other demographic and population parameters such as effective population size, strong selection and founder effects. In the present study we use pedigree records to evaluate these potential impacts on a closed nucleus Angus from U.S. and an open multiplier Nellore herd from Brazil. The combined description of population structure and genetic variability of these two herds indicates that it is possible to maintain genetic variability with medium levels of inbreeding in herds with strong selection and small effective population size. Additionally, the analysis illustrates the importance of pedigree depth for accurately estimating population parameters, particularly, inbreeding and effective population size.
\end{abstract}

Keywords: effective population size, founder effect, genetic gain, inbreeding

\section{Introduction}

Historical pedigree records can be used to identify the factors that have influenced the genetic evolution of a population (Valera et al., 2005). Moreover, some population parameters are strongly dependent on management and mating systems and can have significant impacts on genetic variability. Cattle breeders are typically concerned about the productivity and genetic health of their livestock, both of which can potentially benefit from within-population assessments of genetic variability and population structure. Such assessments can be used to guide selection programs and genetic stock management (Glazewska \& Jezierski, 2004).

A number of studies have documented inbreeding depression in bovine traits (Mc Parland et al., 2007; Carrillo \& Siewerdt, 2010; Santana et al., 2012). However, less experimental work has been conducted on the effects of inbreeding and other parameters (e.g. effective population size, strong selection and founder effects) on the genetic variance. Moreover, the few studies that have been performed have typically used simulations or experiments with invertebrates (Kristensen et al., 2005). Thus, studies using commercial herds in their respective production environments are clearly necessary and desirable. Here, we address this lack by evaluating the population history of two commercial cattle breeds with contrasting population histories: a closed nucleus Aberdeen Angus herd and an open multiplier Nellore herd.

The Wye Angus herd was established in 1937 and the first calf was born in 1939. Since 1958 the herd has been closed to outside breeding (Lingle et al., 2001). This herd is historically important and has considerably contributed to the expansion of the Aberdeen Angus breed throughout the world. The closed nature and the completeness of its records make the Wye Angus herd an ideal candidate for pedigree analysis. An open tropical Nellore multiplier herd from Brazil was also analyzed in order to have comparison parameters and reference points. Purebred animals composed the Bos indicus group; which is a similar size to the Bos taurus herd. However, the zebu group has shallow pedigree. 
Our evaluation includes additional parameters such as effective population size (NE), effective number of founders $\left(f_{e}\right)$, effective number of ancestors $\left(f_{a}\right)$ and average relatedness coefficient (AR), to improve resolution and provide more detailed information than can be obtained by only using inbreeding coefficients. We also assess genetic variability and genetic gain (direct and maternal effect) for the trait weaning weight adjusted at 205 days (W205).

\section{Material and Methods}

\subsection{Data Description}

\subsubsection{Angus}

Pedigree information was recorded for 11,692 individuals from a closed nucleus Aberdeen Angus herd born between 1937 and 2012. Records were obtained from the current owner of the herd, the Wye Research and Education Center at the University of Maryland.

\subsubsection{Nellore}

Pedigree and production records were obtained for 11,954 Nellore bovines born between 1960 and 2012 from a multiplier herd from Northeast Brazil. The data was provided by the Nellore monitoring weight program from the "Associação Brasileira dos Criadores de Zebu - ABCZ” (Brazilian Association of Zebu Breeders).

\subsection{Techniques}

\subsubsection{Pedigree Analysis}

Parameters estimation and pedigree analysis, based on gene origin probabilities, were calculated with the ENDOG 4.8 software(Gutierrez \& Goyache, 2005).

\subsubsection{Generation Interval and Pedigree Completeness}

Average generation intervals for the four gametic pathways were estimated in the following order: sire-son, sire-daughter, dam-son and dam-daughter.

Average generation intervals for the four gametic pathways were estimated in the following order: sire-son, sire-daughter, dam-son and dam-daughter. Pedigree completeness was computed for each animal included in the pedigree. The following parameters were calculated for each individual: 1) Maximum number of generations defined as the number of generations separating the individual from its furthest known ancestor. 2) Equivalent complete generations - computed as the sum over all known ancestors of the terms calculated as the sum of $1 / 2^{n}$, where $\mathrm{n}$ is the number of generations separating the individual from each known ancestor.

\subsubsection{Probability of Gene Origin}

Genetic history was assessed by calculating the effective number of founders and the effective number of ancestors. Effective number of founders $\left(f_{e}\right)$ represents the number of animals which, under random pairings, would produce the same genetic variability as that observed in the study population. This is computed as

$$
f_{e}=\frac{1}{\sum_{k=1}^{f} q_{k}^{2}}
$$

Where, $q_{k}$ is the probability of gene origin for ancestor $k$.

The effective number of ancestors $\left(f_{a}\right)$ represents the minimum number of animals (founders or non-founders) that are necessary to explain the total genetic variation observed in the study population. It is calculated in the same way as effective number of founders:

$$
f_{a}=\frac{1}{\sum_{j=1}^{a} q_{j}^{2}},
$$

Where $q_{j}$ is the marginal contribution of ancestor $j$, representing the genetic contribution made by an ancestor that is not explained by another previously chosen ancestor. This parameter complements the information provided by the effective number of founders by accounting for the loss of genetic variability from the unbalanced use of reproductive individuals (bottleneck effects).

\subsubsection{Inbreeding and Average Relatedness Coefficient (AR)}

The change in inbreeding $(\Delta F)$ were calculated as described by Gutierrez et al. (2009), using the formula:

$$
\Delta F_{i}=1-\sqrt[t-1]{1-f_{i}}
$$

Where $F_{i}$ is the individual inbreeding coefficient and $t$ is the equivalent generation for this individual (Boichard 
et al., 1997). The expression relating inbreeding in generation $t$ with inbreeding rate proposed by Gutierrez et al. (2009) is

$$
F=1-(1-\Delta F)^{t-1}
$$

The average relatedness coefficient of each individual is defined as the probability that an allele randomly chosen from the whole population in the pedigree, belongs to a given animal (Gutierrez \& Goyache, 2005). The average relatedness coefficient can thus be interpreted as a representation of the animal in the whole pedigree regardless of the knowledge of its pedigree.

\subsubsection{Effective Population Size}

The effective size was calculated in three ways: first, an estimate of effective population size $\left(\overline{N_{e}}\right)$ - called "realized effective size" was computed from $\overline{\Delta F}$ - computed by averaging the $\Delta F_{i} s$ of the $\mathrm{n}$ individuals included in a given reference subpopulation, as $\overline{N_{e}}=1 / 2 \overline{\Delta F}$. Additionally, a standard error of $\overline{N_{e}}$ was computed from the standard deviation of $\Delta F$ and the square root of the size (n) of the reference subpopulation as $\sigma_{\overline{N e}}=2 \bar{N}_{e}^{2} \sigma_{\Delta F} \frac{1}{\sqrt{\bar{N}_{e}}}$ (Gutierrez et al., 2008).

Second, the effective populations size $\left(\overline{N_{e c}}\right)$ was estimated from increase in coancestry for all pairs of individuals $j$ and $k\left(\Delta c_{j k}\right)$ in a reference subpopulation (Cervantes et al., 2011). This parameter is computed as

$$
\Delta C_{j k}=1-\left(\frac{g-g_{k}}{2}\right) \sqrt{1-C_{j k}}
$$

where $c_{j k}$ is the inbreeding value corresponding to an offspring from $j$ and $k$, and $g_{j}$ and $g_{k}$ are the discrete equivalent generation of individual $j$ and $k$. By averaging the increase in coancestry for all pairs of individuals in a reference subpopulation, we can estimate a realized effective population size based on coancestries as $\overline{N_{e c}}=\frac{1}{2 \overline{\Delta c}}$ - this value provides information on the effective size of a population under random mating. We also computed the standard error of the $\overline{N_{e c}}$ from the standard deviation of these increases in coancestry $\left(\sigma_{\Delta c}\right)$ and the square root of the effective size of the effective number of paired coancestry in the reference sub population as $\sigma_{\overline{N_{e c}}}=2 N_{e c}{ }^{2} \sigma_{\Delta c} \frac{1}{\sqrt{\frac{\overline{e c c}_{\left.\overline{N_{e c}}-1\right)}^{2}}{2}}}$.

Finally, the effective size $(\mathrm{Ne})$ was calculated from the variances of family sizes as

$$
\frac{1}{N_{e}}=\frac{1}{16 M L}\left[2+\sigma_{m m}^{2}+2\left(\frac{M}{F}\right) \operatorname{cov}(m m, m f)+\left(\frac{M}{F}\right)^{2} \sigma_{m f}^{2}\right]+\frac{1}{16 F L}\left[2+\left(\frac{F}{m}\right)^{2} \sigma_{f m}^{2}+2\left(\frac{F}{M}\right) \operatorname{cov}(f m, f f)+\sigma_{f f}^{2}\right]
$$

Where $M$ and $F$ are the number of male and female individuals born or sampled for breeding each time period (five years), $L$ is the average generation interval $\sigma_{m m}^{2}$ and $\sigma_{m f}^{2}$ are the variances of the male and female offspring of a male, $\sigma_{f m}^{2}$ and $\sigma_{f f}^{2}$ are the variances of the male and female offspring of a female, and cov ( $\left.\mathrm{mm}, \mathrm{mf}\right)$ and cov $(f m, f f)$ are the respective covariances (Hill, 1979).

\subsubsection{Genetic Variance and Genetic Values}

We used data from 8,739 and 7,077 weights adjusted at 205 (W205) days of age, for Angus and Nellore animals. The means for the trait were $231.36 \pm 28.87 \mathrm{~kg}$ (Angus) and $177.36 \pm 28.7 \mathrm{~kg}$ (Nellore).

In order to obtain the (co)variance and genetic value estimates, univariate analyses were performed by Gibbs sampling using GIBBS3F90 (Misztal, 2003). The prior distribution for (co)variance components of maternal and direct additive genetic effects was an inverted Wishart distribution.

We used models that included random genetic effects (direct and maternal), permanent maternal environment, the covariate age of dam at calving (linear and quadratic effect), and the fixed effect of contemporary group (CG). The contemporary groups consisted in animals of the same gender and breed season (year and season). Contemporary groups with less than four individuals were excluded from the analysis. The total contemporary groups were 260 (Angus) and 690 (Nellore).

The initial number of iterations was arbitrarily obtained using a single chain of 200,000 iterations and a burn-in period of 20,000 iterations with a sampling interval of 20. The BOA package was employed in the convergence diagnostic test, following the Geweke method (1992).

\section{Results and Discussion}

\subsection{Generation Intervals}

Wye Angus generation interval estimates for the corresponding pathways were equal to $9.17 \pm 10.33$ (sire-son), 
$6.43 \pm 6.27$ (sire-daughter), $6.43 \pm 6.22$ (dam-son) and $5.37 \pm 3.32$ years (dam-daughter), resulting in an overall average generation interval of $6.14 \pm 5.55$ years. For the Nellore herd the corresponding values were $7.38 \pm 3.28$ (sire-son), $8.29 \pm 4.40$ (sire-daughter), $6.32 \pm 2.76$ (dam-son), $7.13 \pm 3.27$ (dam-daughter) and $7.69 \pm 3.89$ (average interval).

These values are at the high end of previous estimates in cattle. Bozzi et al. (2006) reported intervals ranged from 4.36 to 6.02 in three breeds from Italy while Gutierrez et al. (2003) reported estimates from 3.70 to 6.08 years in the reference populations of eight Spanish beef cattle breeds. However, in contrast to our results, in these two studies the sire-offspring pathway was always lower than the dam-offspring pathway because sires were replaced early and artificial insemination (AI) was widely used.

The high generation intervals for sire pathways are caused by different factors in the two study herds. For the Wye Angus, two factors are important: first, the use of few sires over long periods of herd formation. Specifically, the two sires (Puck of Wickwire and Gaird of Dalmeny) with the largest number of offspring were allowed to breed for 9 years; Second, and probably more importantly, semen from foundation sires was used over the last two decades. Sires are reintroduced back into breeding programs with the aim of enhancing and solidifying key maternal traits and carcass characteristics (Lingle et al., 2001). For the Nellore breed the high generation interval is a consequence of using sires for various reproductive seasons in extensive operations. Indeed, several studies have reported the high average generation intervals (7.3 - Caires et al., 2012; 8.1 - Malhado et al., 2010) in beef cattle from tropical regions.

\subsection{Pedigree Completeness and Generation Number}

The Wye pedigree completeness was very high, especially in the first three generations where values of 99.1, 91.2, and 82.6 percent were obtained (Figure 1). In contrast, the Nellore pedigree completeness was low, with values of 90.1, 44.9 and 16.1 percent for the first, second and third generations. These values suggest that the lack of pedigree completeness for the Nellore breed can seriously confound the estimation of population and genetic parameters.

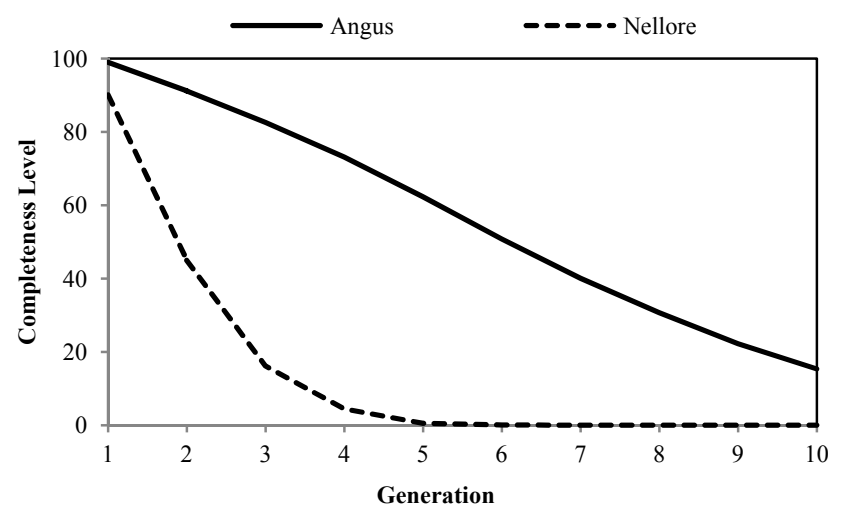

Figure 1. Percentage of known ancestors in the first ten generations in the Nellore and Angus herd

The pedigree completeness result for the Angus herd is broadly in line with a recent study by Marquéz et al. (2010) on 2,141,506 registered Red Angus animals born between 1927 and 2006 from the Red Angus Association of America (RAAA). This study found that more than 94, 92 and 88 percent of all animals in the pedigree have known parents in the first, second and third generations. These values reflect the moment when accurate data recording systems were implemented and could be used as a measure of record quality for data collection systems that started at the same time. American and European associations started earlier, and consequently have more pedigree information than tropical beef cattle associations.

The effective number of founders $\left(f_{e}\right)$ and ancestors $\left(f_{a}\right)$ were much lower for Wye Angus $\left(f_{e}=15\right.$ and $\left.f_{a}=12\right)$ than Nellore $\left(f_{e}=88\right.$; and $f_{a}=87$ ) (Table 1). The ratios of $f_{e}$ to the number of founders were 0.09 (Angus) and 0.07 (Nellore), indicating a high disequilibrium between founder contributions. This reflects an excessive use of some animals as reproducers, especially "good bulls", as is expected in nucleus and multiplier herds. The smaller estimated effective number for the Wye Angus herd is expected, given the long pedigree and the closure of the herd to outside breeding since 1958 . 
Table 1. Parameters characterizing the probability of gene origin in the Nellore and Angus breed

\begin{tabular}{lll}
\hline & Nelore & Angus \\
\hline Size of Population & 11954 & 11692 \\
Population reference & 10750 & 11657 \\
Population base & 1204 & 35 \\
Number of founder animals for the reference population & 1154 & 155 \\
Number of ancestor animals for the reference population & 1138 & 146 \\
Effective number of founder for reference population & 88 & 15 \\
Effective number of ancestor for reference population & 87 & 12 \\
Number of ancestors explaining 50\% variability & 38 & 4 \\
Expected inbreeding caused by unbalanced contribution of Founders \% & 0.47 & 3.37 \\
\hline
\end{tabular}

The extent of the genetic bottleneck expressed by the $\mathrm{f}_{\mathrm{e}} / \mathrm{f}_{\mathrm{a}}$ ratio (effective number of founders/effective number of ancestors) were 1.25 (Angus) and 1.01 (Nellore). This indicates that in addition to the small effective number of founders, the Wye Angus herd also suffered from a bottleneck effect. The $f_{e} / f_{a}$ ratio is caused by a decrease in the number of breeders in any given generation. Furthermore, bottleneck effects are more frequently observed in populations with deep pedigrees (Ghafouri-Kesbi, 2010; Santana et al., 2012).

Only four ancestors explained nearly $50 \%$ of the genetic variability in the Wye Angus population (Table 2). A superior number of ancestors (38) explained the same variability in the Nellore herd. The small number of individuals explaining extensively the genetic variability of the Wye Angus herd is a consequence of the reduced effective number of ancestors. In contrast, the 10 major ancestors for Nellore were used more intensely (over twice as much) than ancestors of the Angus breed. Excessive use of certain individuals as breeding animals can lead to a marked reduction in the genetic stock (Pedrosa et al., 2010). However, our results indicate that the small number of ancestors explaining the genetic variability of the herd is not strongly related to the intensive use of some animals, but is more a consequence of the closure and pedigree depth of the herd.

Table 2. Contribution and accumulated contribution for genetic variability, and progeny number of 10 major ancestors (founders or not) in the Angus and Nelore cattle

\begin{tabular}{llll|llll}
\hline Angus & Cont (\%) & Accum. & Progeny & Nellore & Cont (\%) & Accum. & Progeny \\
\hline Puck of Wickwire & 16.6 & 16.6 & 313 & 1144401 & 5.5 & 5.5 & 560 \\
Gaird of Dalmeny & 12.1 & 28.7 & 231 & 1442095 & 3.9 & 9.4 & 313 \\
Juryman of Wick & 11.2 & 39.9 & 209 & 2860551 & 2.9 & 12.3 & 337 \\
Prince ofMalpas & 9.3 & 49.2 & 145 & 1353767 & 2.8 & 15.1 & 236 \\
Blackapper & 7.2 & 56.4 & 10 & 1491270 & 2.3 & 17.4 & 118 \\
Clarice of Wye & 5.6 & 62.0 & 15 & 1438006 & 1.9 & 19.3 & 228 \\
G. of Swiftbrook & 4.8 & 66.8 & 113 & 2301359 & 1.8 & 21.1 & 318 \\
Backford Buxton & 4.6 & 71.4 & 122 & 1843896 & 1.8 & 22.9 & 244 \\
Valour of Ardrass & 4.6 & 76.0 & 55 & 2138039 & 1.7 & 24.6 & 261 \\
MulbenEnvoist & 3.3 & 79.3 & 139 & 836551 & 1.7 & 26.3 & 187 \\
\hline
\end{tabular}

The unbalanced contribution of founders was much greater in the Wye herd than the Nellore breed, as expected to observe in a closed herd. An unbalanced contribution of founders was also reported by Malhado et al. (2012) for Murrah buffaloes and Santana et al. (2012) for beef cattle.

\subsection{Inbreeding and Average Relatedness Coefficient}

The Wye Herd formation began in the 1940s and consisted of a large proportion of inbred mating, which peaked in 1944 when nearly $45 \%$ of the mating was among close relatives - producing offspring with $\mathrm{F}$ average of 14 percent. The first two sires of the Wye herd participated in 40 and 55 highly inbred matings, resulting from 
crossing with daughters and granddaughters. According to Lingle et al. (2001) the first bull (Blakeford Buxton) was bred to his female descendants for three generations. Since 1965 breeding has been managed to prevent crossings between closely related animals. However, the inbreeding coefficient increased until the 1980s as a result of cumulative inbreeding (Carrillo \& Siewerdt, 2010). In contrast, the Nellore herd shows no evidence of inbred mating, possibly due to the lack of pedigree information at the time. The first inbred mating was registered at the beginning of the $1980 \mathrm{~s}$, as a result of sire-daughter mating.

The average $\mathrm{F}$ values for the reference populations were $7.93 \%$ (Angus) and $0.2 \%$ (Nellore). The means of $\mathrm{F}$ for inbreed animals were 10.06 (Angus) and 6.3 (Nellore) percent. In addition to being higher than the Nellore group, inbreeding in the Wye Angus herd is higher than reported values for most other beef cattle: Brazilian breed $(0.41$ to 2.21\%; Santana et al., 2010), Italian breed (1.8 to 2.15\%; Bozzi et al., 2006), Danish dairy cattle (0.9 to $1.1 \%$; Sorensen et al., 2005), Spanish breed (0.25 to 3.13\%; Gutiérrez et al., 2003), and Japanese Black cattle (5\%, Nomura et al., 2001). It is noteworthy that in all these studies the degree of pedigree completeness was lower than the Wye Angus herd, with the exception of Nomura et al. (2001) who, in any case, did not calculate the pedigree completeness and generation numbers.

A study of the American Hereford pedigree (1900 to 2001) calculated the average inbreeding to be 0.115 in 2001 (Cleveland et al., 2005). The same study calculated mean inbreeding (using the subsample of animals born between 1990 and 2001 with at least 12 generations of pedigree) to further investigate the impact of pedigree completeness. The authors reported an increase to $18 \%$ by 2001 , and almost one-third of animals born in 2001 had inbreeding level exceeding $20 \%$, compared with $6 \%$ of animals using the full pedigree. When we applied the same restriction only to the Wye Angus herd, eliminating animals with less than 12 known generations, inbreeding increased from 7.93 to $10.8 \%$. The relative increase in inbreeding was 36 and $56 \%$ for the Wye Angus and Hereford pedigrees, respectively, emphasizing the importance of a long and complete pedigree to accurately estimate inbreeding and others parameters based on gene origin probabilities.

The increases in inbreeding by known equivalent generation were $0.34 \%$ (Angus) and $1.51 \%$ (Nellore). This result highlights that the bias in herds with high and cumulative inbreeding can be up to 5 times greater than in herds with low inbreeding.

The average relatedness coefficients between individuals of the population were estimated at $14.49 \%$ (Angus) and $1.1 \%$ (Nellore). Despite the high average for the Wye Angus, there is wide variation in the values of individual AR (0.0001 to 0.23 ). One possible management strategy based on this information could be to use the average relatedness coefficient to guide sire selection. Average relatedness coefficients can be employed to estimate long-term inbreeding of a population and to suggest modifications on management practice for conserving the genetic variability in a population (Goyache et al., 2010). A very high average relatedness coefficient indicates that the parents of an individual have close common ancestors, while a low average relatedness coefficient indicates that the animal share common ascendant alleles with only a relatively small proportion of the population. Thus, livestock breeders should use individuals with the lowest possible AR coefficients for preventing inbreeding accumulation. Breeders can also use this information to indirectly characterize the herds as sub-components of the entire breed population. The AR values of the individuals included in a herd can be used as an indicator of the degree of inbreeding and coancestry within each herd. If relatively high AR values are observed in a herd, it should be opened up to under-represented animals (Goyache et al., 2003).

\subsection{Effective Size}

For the Wye Angus, the effective size computed via individual increase in coancestry $\left(\bar{N}_{e c}\right)$ was $26.23 \pm 0.75$, an estimate that was close to the effective size computed by individual increase $\bar{N}$ e in inbreeding (29.47 \pm 7.09 ). The lower value for $\bar{N}$ ec reflects a small degree of population subdivision - this occurred in the 1990's (as reported above). For the Nellore breed, the parameters $\bar{N}$ ec and $\bar{N}$ e were $58.36 \pm 3.35$ and $103.68 \pm 36.89$, respectively. The large discrepancy between the parameters and the estimates is probably due to the low completeness and shallow pedigree of the Nellore herd. When pedigree information is incomplete the computed inbreeding is biased downward and the realized effective size is overestimated (Boichard et al., 1997). The magnitudes of the standard error between the two herds indicate more accurate estimates for the Wye Angus herd. Indeed, a recent study with seven breeds with different population structures reported the same relationship between standard error and number of equivalent generations known (Cervantes et al., 2011).

The ratio $\bar{N}$ ec/ $/ \bar{N}$ e were 0.88 (Angus) and 0.56 (Nellore). In an idealized population the expected value is close to 1 . According by Gutierrez et al. (2008) the comparison between $\bar{N}$ ec and $\bar{N}$ e gives valuable information about the population structure. The two parameters are assumed to be measures of the same accumulated drift 
process in the population, from the foundation to the present. As they would be asymptotically equivalent in an idealized population, the lack of concordance between them is mainly caused by their differential ability to assess the effect of preferential mating. In other words, the comparison between the two parameters characterizes the influence of preferential mating in the population.

The effective sizes per generation calculated from the variances of family sizes were below 40 until the beginning of the 1980s for both breeds. From this decade onwards the effective sizes oscillated, but were always greater than 40 (Figure 2). The peak for the Wye Angus herd occurred in the beginning of the 1990s as a consequence of the acquisition of new sires.

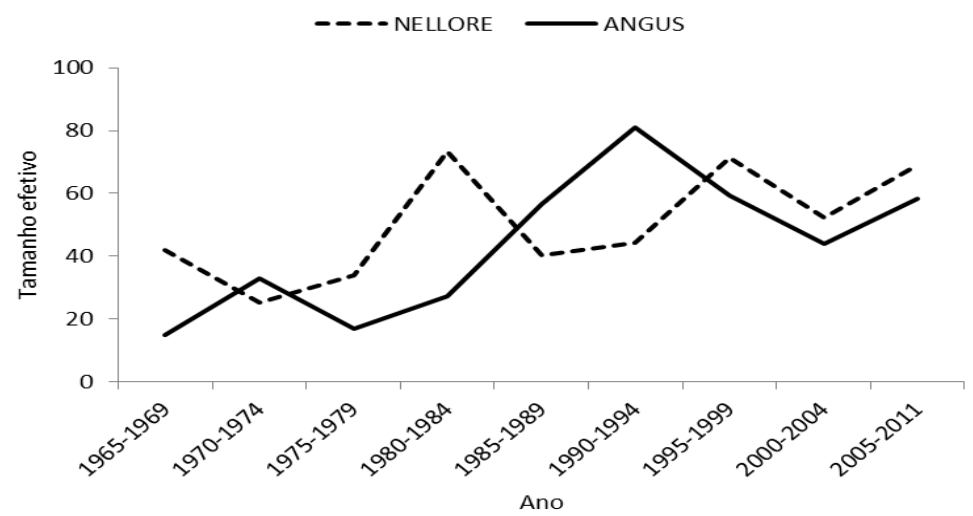

Figure 2. Effective size per generation calculated from the variances of family sizes for Nelore and Angus herds

Gutierrez et al. (2008) have argued that Ne computed from variances of family sizes was not useful to characterize the 'real' effective size. However, Ne calculated in this way does reflect a temporary mating policy, and can therefore be useful when pedigree knowledge is limited and/or subdivision has not yet occurred.

\subsection{Genetic Gain, Genetic Variability and Genetic-Maternal Correlation}

The direct and maternal heritability coefficients (mode) were 0.17 and 0.11 (Nellore) and, 0.27 and 0.13 (Angus).The Wye Angus herd showed strong selection for direct and maternal effects in the W205 trait, with high genetic gain (Figure 3) - close to $20 \mathrm{~kg}$ (direct) and $17 \mathrm{~kg}$ (maternal) over the 46 year study period. Lingle et al. (2001) reported that, from 1954 to 1974, bulls were selected for weight gain resulting in a large phenotypic gain per generation during this period. However, they also mentioned that in the later generations the increments of progress started to reduce. Moreover, the same authors reported that the Wye herd was exposed to a strong selection for maternal effects (dams'milk quality). This later finding agrees with the extensive maternal genetic gain observed in the present study.

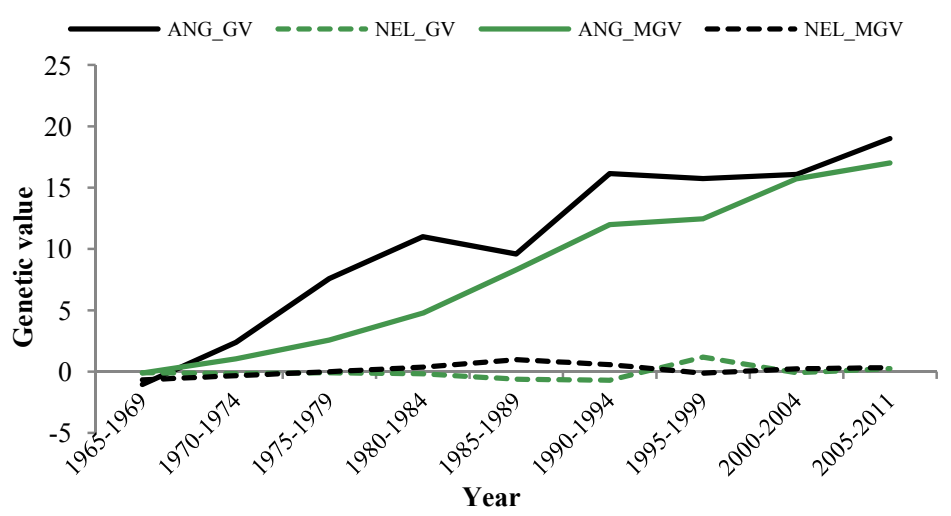

Figure 3. Genetic gain for direct (GV) and maternal effect (MGV) for Nellore (NEL) and Angus (ANG) herd

The Nellore herd had a very small genetic gain during the same period of time; below $0.5 \mathrm{~kg}$ for both effects. 
Animals under traditional livestock management conditions are typically selected by breeders based on anatomical and racial traits rather than on a basis of productive or reproductive performance. Nevertheless, this trend has decreased over recent years while the use of breeding values have increased in some Nellore herds in the northeastern region (Malhado et al., 2008).

The variance of the direct genetic values for the Wye Angus herd decreased from 1965 to 1975, possibly as a result of strong selection (Figure 4). The period from 1975 to 1979 was characterized by the smallest effective size for the Wye Angus herd, possibly as a result of a bottleneck effect. However, the genetic variance increased in the following years. The outcome of this apparent paradox may be related to how additive genetic variance, the genetic factor determining response to selection, is changed by passage through a population bottleneck (Taft $\&$ Roff, 2012). An increase in additive genetic variance is possible if there is dominance or epistatic variance present in the population (Barton \& Turelli, 2004). The peak for genetic variance occurred the 1990s due to the acquisition of new bulls. However, the non-Wye sires were removed from the herd in 1996, corresponding with a return to similar variance levels as those observed in the 1980's.

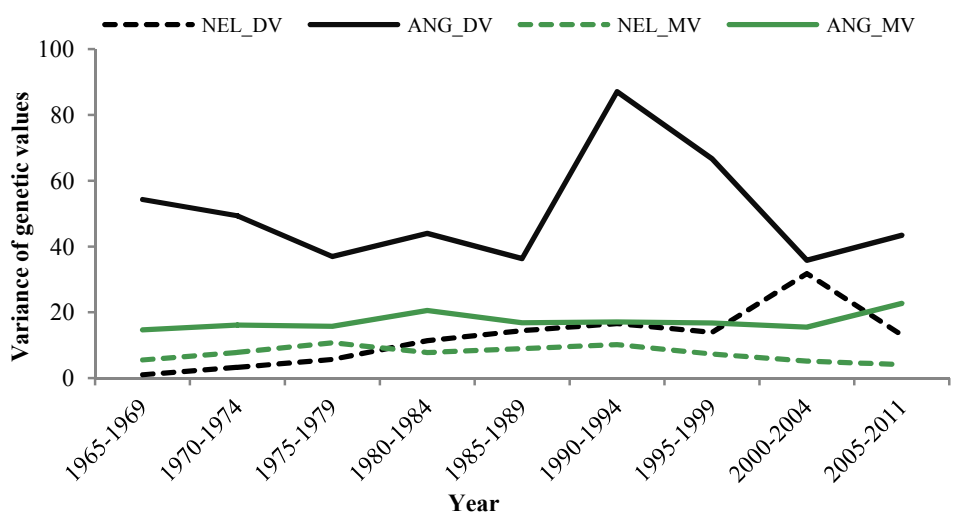

Figure 4. Variance of genetic values for direct (DV) and maternal effect (MV) for Nellore (NEL) and Angus (ANG) herd

Maternal and direct genetic variances for Nellore herd were lower than the Wye Angus over the entire study period. Some factors such as small magnitude of heritability, dissimilar trait averages (Nellore $=177.4 \mathrm{~kg}$, Angus $=231.4 \mathrm{~kg}$ ) and the large number of offspring from the most important Nellore sires may explain this difference. The results confirm that the Wye Angus herd has been closed (except for a short period) and has a very low number of ancestors, which are responsible for the genetic variability. Additionally the herd suffered high inbreeding, small effective size and strong selection - the present genetic variability is close to the value at the beginning and is higher than the open Nellore herd over all years. It is generally assumed that inbreeding reduces the additive genetic variance within populations (Kristensen et al., 2005; Sorensen et al., 2005). However, the association between inbreeding level and additive genetic variance is less predictable with lower levels of inbreeding.

\section{Conclusion}

No clear connection was observed between genetic variance and any population genetic parameters (inbreeding, strong selection, small effective size, and a reduced ancestor number). It is also clear that knowledge of several generations provides better estimates of effective population size and inbreeding for herds with middle and cumulative consanguinity.

\section{References}

Barton, N. H., \& Turelli, M. (2004). Effects of genetic drift on variance components under a general model of epistasis. Evolution, 58, 2111-2132. http://dx.doi.org/10.1111/j.0014-3820.2004.tb01591.x

Boichard, D., Maignel, L., \& Verrier, E. (1997). The value of using probabilities of gene origin to measure genetic variability in a population. Genetics Selection Evolution, 29, 5-23. http://dx.doi.org/10.1186/1297-9686-29-1-5

Bozzi, R. et al. (2006). Genetic variability in three Italian beef cattle breeds derived from pedigree information. Italian Journal of Animal Science, 5, 129-137. 
Carneiro, P. L. S. et al. (2009). The Indubrasil breed in the Brazilian Northeast: breeding and population structure. Revista Brasileira De Zootecnia-Brazilian Journal of Animal Science, 38, 2327-2334. http://dx.doi.org/10.1590/S1516-35982009001200006

Carrillo, J. A., \& Siewerdt, F. (2010). Consequences of long-term inbreeding accumulation on preweaning traits in a closed nucleus Angus herd. J. Anim. Sci., 88, 87-95. http://dx.doi.org/10.2527/jas.2009-1897

Cervantes, I., Goyache, F., Molina, A., Valera, M., \& Gutierrez, J. P. (2011). Estimation of effective population size from the rate of coancestry in pedigreed populations. J. Anim. Breed Genet., 128, 56-63. http://dx.doi.org/10.1111/j.1439-0388.2010.00881.x

Ghafouri-Kesbi, F. (2010). Analysis of genetic diversity in a close population of Zandi sheep using genealogical information. J. Genet., 89, 479-483. http://dx.doi.org/10.1007/s12041-010-0068-0

Glazewska, I., \& Jezierski, T. (2004). Pedigree analysis of Polish Arabian horses based on founder contributions. Livestock Production Science, 90, 293-298. http://dx.doi.org/10.1016/j.livprodsci.2004.08.002

Goyache, F. et al. (2010). Demographic and genetic analysis of the Mallorquina sheep flockbook. Itea-Informacion Tecnica Economica Agraria, 106, 3-14.

Gutierrez, J. P., \& Goyache, F. (2005). A note on ENDOG: a computer program for analysing pedigree information. J. Anim. Breed Genet., 122, 172-176. http://dx.doi.org/10.1111/j.1439-0388.2005.00512.x

Gutierrez, J. P., Cervantes, I., \& Goyache, F. (2009). Improving the estimation of realized effective population sizes in farm animals. J. Anim. Breed Genet., 126, 327-332. http://dx.doi.org/10.1111/j.1439-0388.2009.00810.x

Gutierrez, J. P., Cervantes, I., Molina, A., Valera, M., \& Goyache, F. (2008). Individual increase in inbreeding allows estimating effective sizes from pedigrees. Genetics Selection Evolution, 40, 359-378. http://dx.doi.org/10.1186/1297-9686-40-4-359

Hill, W. G. (1979). A note on effective population size with overlapping generations. Genetics, 92, 317-322.

Kristensen, T. N. et al. (2005). A test of quantitative genetic theory using Drosophila- effects of inbreeding and rate of inbreeding on heritabilities and variance components. J. Evol. Biol., 18, 763-770. http://dx.doi.org/10.1111/j.1420-9101.2005.00883.x

Malhado, C. H. et al. (2012). Population structure and genetic variability in the Murrah dairy breed of water buffalo in Brazil accessed via pedigree analysis. Trop Anim Health Prod. http://dx.doi.org/10.1007/s11250-012-0153-x

Malhado, C. H. M. et al. (2010). Genetic improvement and population structure of the Nelore breed in Northern Brazil. Pesquisa Agropecuaria Brasileira, 45, 1109-1116. http://dx.doi.org/10.1590/S0100-204X2010001000009

Marquez, G. C., Speidel, S. E., Enns, R. M., \& Garrick, D. J. (2010). Genetic diversity and population structure of American Red Angus cattle. J. Anim. Sci., 88, 59-68. http://dx.doi.org/10.2527/jas.2008-1292

Mc Parland, S., Kearney, J. F., Rath, M., \& Berry, D. P. (2007). Inbreeding effects on milk production, calving performance, fertility, and conformation in Irish Holstein-Friesians. J. Dairy Sci., 90, 4411-4419. http://dx.doi.org/10.3168/jds.2007-0227

Nomura, T., Honda, T., \& Mukai, F. (2001). Inbreeding and effective population size of Japanese Black cattle. $J$. Anim. Sci., 79, 366-370.

Pedrosa, V. B., Santana, M. L., Oliveira, P. S., Eler, J. P., \& Ferraz, J. B. S. (2010). Population structure and inbreeding effects on growth traits of Santa Ines sheep in Brazil. Small Ruminant Research, 93, 135-139. http://dx.doi.org/10.1016/j.smallrumres.2010.05.012

Santana, M. L. Jr., Oliveira, P. S., Eler, J. P., Gutierrez, J. P., \& Ferraz, J. B. (2012). Pedigree analysis and inbreeding depression on growth traits in Brazilian Marchigiana and Bonsmara breeds. J. Anim. Sci., 90, 99-108. http://dx.doi.org/10.2527/jas.2011-4079

Sorensen, A. C., Sorensen, M. K., \& Berg, P. (2005). Inbreeding in Danish dairy cattle breeds. J. Dairy Sci., 88 , 1865-1872. http://dx.doi.org/10.3168/jds.S0022-0302(05)72861-7

Taft, H. R., \& Roff, D. A. (2012). Do bottlenecks increase additive genetic variance? Conservation Genetics, 13, 333-342. http://dx.doi.org/10.1007/s10592-011-0285-y 
Valera, M., Molina, A., Gutierrez, J. P., Gomez, J., \& Goyache, F. (2005). Pedigree analysis in the Andalusian horse: population structure, genetic variability and influence of the Carthusian strain. Livestock Production Science, 95, 57-66. http://dx.doi.org/10.1016/j.livprodsci.2004.12.004

Van Grevenhof, E. M., Van Arendonk, J. A. M., \& Bijma, P. (2012). Response to genomic selection: The Bulmer effect and the potential of genomic selection when the number of phenotypic records is limiting. Genetics Selection Evolution, 44, 26. http://dx.doi.org/10.1186/1297-9686-44-26

\section{Copyrights}

Copyright for this article is retained by the author(s), with first publication rights granted to the journal.

This is an open-access article distributed under the terms and conditions of the Creative Commons Attribution license (http://creativecommons.org/licenses/by/3.0/). 